the re-emergence of the power of the "shakti" throughout Indian society.

\section{ReFERENCES}

1. Rohde JE. Health, nutrition and education of girls in India : An integrated approach. Education and Social Change 1987; $1:$ :73-74.

2. Vir $\mathbf{S}$. Adolescent growth in girls-the Indian perspective. Indian Pediatr 1990; 27 : 1249-1255.

3. National perspective plan for women 1988-2000 A.D. Department of Women and Child Development, Government of India. 1988.

4. Gopalan C. The female adolescent (mother-to-be) : The key to nutritional up liftment and national development. NFI Bulletin 1984; 296-303.
5. Facts for life, A communication challenge. UNICEF, New York. 1990.

6. Rohde JE. Mother's milk and the Indonesian economy. J Trop Pediatr 1982; 28 : 166-174.

7. Bennett L. Gender and poverty in India : Issues and opportunities concerning women in the Indian economy. The World Bank 1989.

8. Yunus M. Right to a life with dignity. The South Asian child-Strategies for the nineties. UNICEF, New Delhi, 1989; 21.

9. Status paper on Adolescent gir, 1990. Department of Women and Child Development, Ministry of Welfare, Government of India.

10. Rohde JE. Principles and strategies of programming for adolescent girls. Indian J Matemal and Child Health 1990; 1 : 3-7.

\title{
MANAGEMENT OF URINARY TRACT INFECTION
}

After an appropriate specimen of urine has been obtained, treatment should immediately be started, especially in infants under 2 years old, with the 'best guess' antibacterial agent in full dosage. It can be changed if necessary after 48 hours when drug sensitivities of the organism are available or if there has been no clinical response. Drugs suitable for oral administration for short full-dose courses include cotrimoxazole, trimethoprim, nitrofurantion and orally administered cephalosporins.

A course of 5-7 days is usually prescribed but the optimum length of treatment is not known. After the short course of treatment the urine should be examined to ensure that the infection has been eradicated. Prophylactic antibiotics should not be stopped while the urine is collected.

A low dose of a suitable antibacterial drug should be continued prophylactically at least until investigation of the urinary tract has been completed. Agents currently suitable for prophylaxis include trimethoprim $(1-2 \mathrm{mg} / \mathrm{kg} /$ day), co-trimoxazole (trimcthoprim $1-2 \mathrm{mg}$ and sulphamethoxaxole $5-10 \mathrm{mg} / \mathrm{kg} /$ day) and nitrofurantion $(1 \mathrm{mg} / \mathrm{kg} /$ day $)$. Amoxycillin is not satisfactory.

In children under 5 years old and those with demonstrated abnormalities on imaging, urine microscopy and culture should be carried out one every 3 months for at least 2 years or at times when they are feverish or unwell. 